\title{
MEDIAÇÃO DE CONFLITOS, JUSTIÇA RESTAURATIVA: CAMINHOS PARA UMA ESCOLA MAIS JUSTA?'
}

\author{
CONFLICTS MEDIATION, RESTORATIVE JUSTICE: \\ PATHS TO A FAIRER SCHOOL?
}

\author{
MEDIACIÓN DE CONFLICTOS, JUSTICIA RESTAURATIVA: \\ CAMINOS PARA UNA ESCUELA MÁS JUSTA?
}

Flávia Inês Schilling ${ }^{1}$

\section{RESUMO}

Apresentaremos alguns resultados da pesquisa Justiça, direitos humanos e violência: a escola justa e as práticas da justiça restaurativa, no marco do projeto Justiça e Educação ${ }^{2}$, uma política pública da SEE/São Paulo, que propõe, entre outras medidas, a formação de professores mediadores e a justiça restaurativa nas escolas. Realizamos um estudo da política, uma revisão bibliográfica e aplicamos questionários e entrevistas com professoras(es) mediadoras(es). As perguntas sobre o que seria o "justo" foram: uma escola com as relações escolares judicializadas seria uma escola mais justa? A formalização das práticas de justiça leva a mais justiça? O professor justo é aquele que recebeu o título de professor mediador? Os resultados nos mostram os dilemas de uma política hesitante e o difícil lugar que estes professores ocupam nas escolas.

PALAVRAS-CHAVE: Justiça. Direitos humanos. Escola justa. Mediação. Violência.

\begin{abstract}
We present some findings from the research Justice, human rights and violence: the fair school and the initiatives of restorative justice, in the context of the project Justice and Education, a public policy set forth by São Paulo's Department of Education and that suggests, among other measures, the preparation of mediators/teachers and restorative justice in schools. We conduct a case study of said public policy, a literature review and apply questionnaires and interviews to the teachers/mediators. The questions regarding what would be 'fair' were: a school with judicial disputes arising from its relations would be fair? The formalization of the practices of fairness effectively increases the degree of fairness? A fair teacher is whom received the title of mediator/teacher? The results show the dilemmas of an uncertain and hesitant public policy and the difficult positions these teachers occupy in schools.
\end{abstract}

KEYWORDS: Justice. Human rights. Fair school. Violence. Mediators.

\footnotetext{
${ }^{1}$ Doutora em Sociologia - Universidade de São Paulo (USP) - São Paulo, SP - Brasil - Professora Doutora Universidade de São Paulo (USP) - São Paulo, SP - Brasil. E-mail: flaviaischilling@gmail.com ORCID ID: https://orcid.org/0000-0001-5126-8507

2 Pesquisa realizada com o apoio do CNPq, Bolsa PQ, 2012 - 2016.
}

(C) ETD- Educação Temática Digital Campinas, SP $\quad$ v.20 $\quad$ n.2 $\quad$ p. $325-342 \quad$ abr./jun. 2018




\section{RESUMEN}

Presentaremos algunos resultados de la investigación denominada Justicia, derechos humanos y violencia: la escuela justa y las prácticas restaurativas, en el marco del proyecto Justicia y Educación, una política pública de la SEE/São Paulo, que propone, entre otras medidas, la formación de profesores mediadores y la justicia restaurativa. Hicimos un estudio de la política, una revisión de la bibliografía y aplicamos cuestionario y entrevistas con profesoras(es) mediadoras(es). Las preguntas sobre lo que seria lo "justo" fueron: una escuela con las relaciones escolares judicializadas seria una escuela más justa? La formalización de las prácticas de justicia llevaría a más justicia? El profesor justo es aquél que recibió el título de profesor mediador? Los resultados nos muestran los dilemas de una política con hesitaciones y el difícil lugar ocupado por eses profesores en las escuelas.

PALABRAS CLAVE: Justicia. Derechos humanos. Escuela justa. Mediación. Violencia.

\section{A PESQUISA, SEU MARCO E CONTORNOS}

O marco da discussão sobre as práticas que estão acontecendo no âmbito da microjustiça escolar é o dado por Bauman (1982) quando propõe discutir a justiça ligada à democracia e aos direitos humanos, tendo como horizonte a redução da violência. Segundo ele,

\footnotetext{
Não é preciso mencionar que o problema da justiça não pode ser sequer postulado a menos que já haja um regime democrático de tolerância que assegure, em sua constituição e na prática política, os direitos humanos - ou seja, o direito de conservar a própria identidade e singularidade, sem risco de perseguição (BAUMAN, 1998, p. 82).
}

Essa articulação, mais reconhecida nas discussões sobre segurança pública e justiça, como, por exemplo, nas análises sobre as formas de punir contemporâneas (SLAKMON; MACHADO; BOTTINI, 2006), sugere a busca por novas formas de inter-relação, com os temas mencionados não podendo ser discutidos de forma isolada ou separada.

Cabe assinalar a importância das leituras de Derrida (2007, 2005), Fraser (2008); Ricoeur (2008), centrais no debate sobre justiça e o justo. Michel Foucault (2010, p. 4) nos auxiliou na organização da perspectiva metodológica do trabalho a partir de sua análise dos "focos de experiência" ou "matrizes da experiência", que articulam, uns sobre os outros, as formas de um saber possível, as matrizes normativas de comportamento para os indivíduos e os modos de existência virtuais para sujeitos possíveis com as vertentes da verdade, do poder e do sujeito vistos como campos heterogêneos e interpenetrados, sobrepostos e em constante tensão e deslocamento uns em relação aos outros.

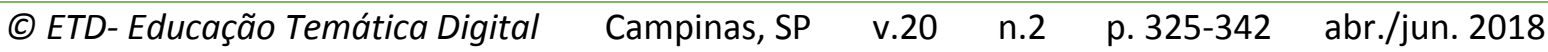


Alguns resultados obtidos sobre o tema nos mostraram o quão difícil e desafiador é imaginar a escola justa. Mesmo o ponto de partida da maioria das pesquisas, dado por Dubet (2008), revela-se problemático, sempre precário, instável. Esta é uma questão reconhecida na literatura sobre o tema:

Ao contrário dos desastres que podem ser universalmente reconhecidos como prejudiciais e indesejáveis, uma vez que golpeiam a esmo e não prestam atenção a privilégios conquistados ou herdados, a justiça é um ponto notoriamente contencioso (BAUMAN, 1998, p. 74).

São, assim, dilemas e possibilidades que permeiam a ação das escolas, mas que derivam de uma confiança primeira, ou seja, a da existência de espaços de independência entre as esferas que fazem com que as escolas não reproduzam ou recriem cegamente as desigualdades e injustiças sociais.

A escola cria suas próprias desigualdades, a economia cria suas próprias desigualdades, a cultura cria suas desigualdades, a política cria suas desigualdades... as desigualdades de cada um desses domínios podem e precisam ser combatidas. Mas há desigualdades e injustiças novas quando as desigualdades produzidas por uma esfera de justiça provocam automaticamente desigualdades em outra esfera. (DUBET, 2004, p. 549).

Um sistema justo deveria assegurar certa independência entre estas esferas. Dubet (2004) sugere que esta independência pode existir e as ações justas - ou que tendem a não reproduzir mecanicamente a injustiça - deveriam comportar uma combinação das ações listadas: modelo meritocrático, discriminação positiva, acesso a bens escolares fundamentais, um mínimo escolar, utilidade dos diplomas, velar para que as desigualdades escolares não reproduzam as desigualdades sociais, tratar bem os "vencidos".

Como essas articulações e debates repercutem nas políticas públicas que tentam dar conta das questões da violência nas escolas? Há, na Secretaria Estadual de Educação de São Paulo, uma série de ações que pretendem articular justiça, direitos, violência, educação. Destacaremos o projeto Justiça e Educação e o Sistema de Proteção Escolar.

Em andamento desde 2006, o projeto instituiu em 2009 uma "Comissão Permanente de Estudos para a implementação do Programa Justiça e Educação: Parceria para a Cidadania", com o objetivo de avaliar, analisar e propor a ampliação e continuidade do programa na rede pública estadual. Este projeto foi contemplado no Prêmio Nacional de Educação em Direitos Humanos de 2009. A ampliação do projeto justifica-se da seguinte forma:

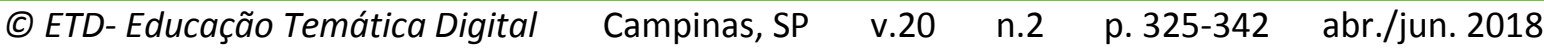


O sucesso das ações do projeto aliado à necessidade de se pensar em práticas que contribuam para que as escolas e comunidades, que vivenciam situações de violência, transformem-se em espaços de diálogo e resolução pacífica de conflitos, fez com que, mais uma vez, suas ações fossem ampliadas. ${ }^{3}$

Segundo o documento, o projeto Justiça e Educação busca desfazer a associação entre jovens e violência pela capacitação de atores sociais das escolas e comunidades, com participação de representantes das Varas da Infância e Juventude e a prática da justiça restaurativa para lidar com situações de conflito envolvendo a comunidade escolar. Instituído a partir de 2009, o Sistema de Proteção Escolar, ${ }^{4}$ junto com as Normas Gerais de Conduta Escolar,

articula um conjunto de ações, métodos e ferramentas que visam disseminar e articular práticas voltadas à prevenção de conflitos no ambiente escolar, à integração entre a escola e a rede social de garantia dos direitos da criança e do adolescente e à proteção da comunidade escolar e do patrimônio público.

Foi também implantado o Sistema Eletrônico de Registro de Ocorrências Escolares (ROE), que permite aos gestores da rede registrar situações de risco e de indisciplina que afetam as escolas estaduais.

A função de professor mediador escolar e comunitário foi criada em março de 2010, como parte do Sistema de Proteção Escolar, para proteger as escolas da rede estadual de fatores de risco e vulnerabilidade e aproximar a comunidade da escola.

Em abril de 2011, aconteceu a abertura de processo de inscrição para professores interessados em atuar como professores mediadores escolares e comunitários (PMECs). ${ }^{5}$

Cabe recuperar uma pergunta: é a justiça irredutível ao direito? Uma escola com as relações escolares judicializadas é uma escola mais justa? A formalização das práticas de justiça leva a mais justiça? O professor justo é aquele que recebeu o título de professor mediador? Não é possível ser justo sem ter tido a capacitação?

Citando a análise de Tibério (2011, p. 26) sobre a temática:

3 Disponivel em: http://www.fde.sp.gov.br/PagesPublic/Noticias.aspx?contextmenu=buscaspub\&noticia=692. Acesso em: 15 jul. 2011.

4 Dialogando, de uma maneira direta, com a proposta do Programa Nacional de Direitos Humanos, decreto 7.037/2009: Eixo Orientador III; Diretriz 8; Objetivo estratégico III; Ações programáticas: d) Implantar sistema nacional de registro de ocorrência de violência escolar, incluindo as práticas de violência gratuita e reiterada entre estudantes (bullying), adotando formulário unificado de registro a ser utilizado por todas as escolas. MEC, 2009. A resolução em questão é a Resolução SE no 19, de 12 de fevereiro de 2010. Disponível em: http://lise.edunet.sp.gov.br/sislegis/detresol.asp?strAto=201002120019 Acesso em: 15 abr. 2010.

5 Disponível em: http://www.fde.sp.gov.br/PagesPublic/Noticias.aspx?contextmenu=buscaspub\&noticia=224 $\underline{224}$ Acesso em: 15 jul. 2011.

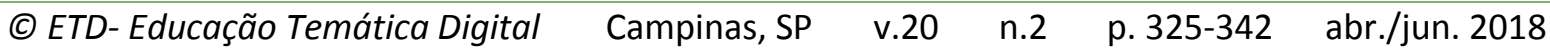


Para garantir os direitos dos alunos, cria-se uma trama que torna perigosa a função de professor, para garantir o bem-estar de professores, os alunos tornam-se alvos de procedimentos punitivos "mais adequados", para garantir a "qualidade" da educação disseminam-se iniciativas de controle e vigilância sobre todos, o que tem tornado a vida no interior das escolas algo extremamente desgastante. De maneira mais direta, é como se o que tem visado promover o bem-estar venha produzindo mais mal-estar, e, isso é importante, não de forma contraditória, mas sim estratégica. Nesse sentido, podemos considerar que ao se buscar a garantia de justiça do ponto de vista de um segmento que compõe a escola, por meio da objetivação e normatização de certas condutas, se tem criado uma condição de fragilidade de outro segmento e assim incitado esse à demanda de garantias através do mesmo mecanismo. É necessário proteger os alunos dos professores, é necessário proteger os professores dos alunos, é necessário proteger a escola de alunos e professores, no limite, é necessário proteger a sociedade.

Estamos, assim, propondo trabalhar nas tensões, na densidade do debate, superando, quem sabe, aquilo que aparece como óbvio ou evidente, exercitando a possibilidade de que nosso olhar seja mais livre sobre as tramas da contemporaneidade, que inserem, na educação, de forma peculiar, os dilemas da sociedade do risco e da insegurança.

Sustentamos que essas práticas produzem efeitos, não apenas nos alunos, mas também nos professores e gestores escolares, modificando profundamente modos de se relacionar, as possibilidades de educar e diferentes compreensões sobre o que é uma escola.

Cabe, assim, demarcar que a pesquisa contou com alguns passos:

a) análise dos materiais produzidos sobre a relação justiça-educação no marco das políticas públicas do Estado de São Paulo, verificando apoios teóricos citados, concepção de justiça, educação e violência, propostas de atuação, integração (ou não) ao marco dos direitos humanos;

b) sistematização do material existente sobre mediação e justiça restaurativa nas escolas;

c) verificação e análise do perfil e da formação dos professores mediadores escolares e comunitários e pesquisa específica com um grupo de PMECs (questionários aplicados em 25 professores mediadores e entrevistas em profundidade com quatro) assim como entrevistas com oito professores que iniciam trabalho com justiça restaurativa em duas escolas da rede municipal de São Paulo.

Não pretendemos, na pesquisa atual, esgotar a análise dos efeitos sobre os modos de ser dos sujeitos afetados pela política ou pelas normas que as envolvem, mas apontar possíveis efeitos, sabendo que não há inevitabilidade ou fatalidade: há resistências sempre inesperadas, efeitos imprevistos.

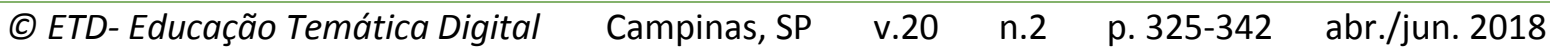


candidatos. Estas atividades tinham como objetivo central reunir os professores mediadores de escolas da região com o objetivo geral de promover a cultura da paz estabelecendo uma rede de proteção com a colaboração de órgãos públicos e organizações da sociedade civil local. Contou com encontros regulares mensais no segundo semestre de 2014. Os objetivos específicos listados foram:

a) identificar tipos de vulnerabilidade apresentados pelas escolas;

b) estabelecer instrumentos para construir redes de proteção à criança e ao adolescente das escolas da DER;

c) fortalecer as equipes gestoras e conselhos de escola de forma a proporem encaminhamentos e ações na resolução dos problemas com vistas aos valores como a amizade, solidariedade e coparticipação nas decisões;

d) colaborar com a formação do professor mediador para o exercício da função mediante ação colaborativa junto a outras instituições locais e organizações da sociedade civil;

e) utilizar o Registro de Ocorrências Escolares (ROE) informatizado como ferramenta de monitoramento das escolas especialmente vulneráveis;

f) utilizar dados de órgãos públicos e institucionais para análise e construção.

Ou seja, foi um curso voltado para as necessidades da função dos PMECs, um fórum de troca de experiências e subsídios para a ação.

O primeiro elemento que chamou a nossa atenção é a idade dos professores mediadores. A média de idade encontrada é de 49 anos. A pessoa mais jovem tem 30 anos e temos a mais velha de 65 anos. São dez professores(as) mediadores(as) na faixa dos 50 anos. É possível apenas levantar hipóteses a serem testados posteriormente: professores em final de carreira, professores " $F$ " (temporários) com muitos anos de casa que encontram na função uma possibilidade de outro tipo de trabalho, pessoas que derivaram suas carreiras de outros ramos para a educação, principalmente a partir dos anos 2000 (conforme atestado pela resposta de quando se formaram). O grupo que respondeu aos questionários foi formado por 21 mulheres e 4 homens, revelando a predominância do sexo feminino nestas funções que implicam "cuidar" do outro.

Todas(os) fizeram sua formação em Faculdades/Universidades particulares, com um perfil predominante em pessoas formadas em Pedagogia e Letras.

\section{A ESCOLHA E SEUS PONTOS POSITIVOS}

Quando se pergunta o porquê do seu interesse em ser um(a) professor(a) mediador(a) e quais os pontos positivos, destacamos a adesão à função por ser uma nova experiência, talvez revelando o cansaço com o lugar habitual de professor em sala de aula.

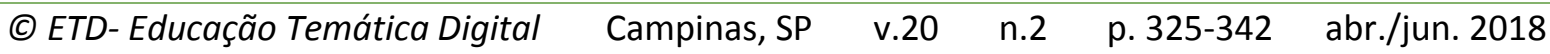


Uma expressão é reiterada: é a da busca por "algo diferenciado", trabalhar com as diferenças, aprender com as diferenças.

Outro termo reiterado é o termo "gosto": gosto de trabalhar com conflitos, gosto de resolver situações, gosto de dialogar com alunos. Parece haver um núcleo nessa função que é atraente: a possibilidade de conversar, de dialogar com todos. Essa é uma ausência constatada em pesquisa anterior (SCHILLING, 2013). A escola seria um lugar de silêncios, mesmo quando muito barulhenta. Há pouco diálogo entre adultos, entre adultos e jovens e crianças, dos jovens e crianças entre si. Conversar é, de fato, um dos tópicos do que seria uma escola justa.

O termo "conflitos" aparece como o cerne da função na maioria dos escritos. "Gosto de trabalhar com conflitos" e "Gosto de ajudar e orientar pessoas" poderiam ser uma síntese de várias respostas a este item do questionário.

Nos pontos positivos listados aparece fortemente a questão de lidar com conflitos, mostrando o peso das formações que tentam colocar o conflito em seu lugar constitutivo e mostrar que é possível lidar com eles. Estes conflitos são nomeados na forma do bullying, preconceito e violência. Já chamamos a atenção para o fato de que, de todas as funções do PMEC listadas na Resolução SE n.o 7, de 2012, parece que as que estão sendo possíveis são as seguintes:

II - orientar os pais dos alunos, ou responsáveis, sobre o papel da família no processo educativo; $[\ldots]$

IV - orientar a família, ou responsáveis, quanto à procura de serviços de proteção social; (SÃO PAULO, 2012).

Parece que a função de conversar, "ser um porto seguro" onde o aluno e sua família possa fazer "confidências" e orientar são as mais visíveis e possíveis e são entendidas como importantes para evitar conflitos maiores.

Quanto às demais possibilidades de atuação, encontram-se:

I - adotar práticas de mediação de conflitos no ambiente escolar e apoiar o desenvolvimento de ações e programas de Justiça Restaurativa; [...]; III - analisar os fatores de vulnerabilidade e de risco a que possam estar expostos os alunos; [...]; $\vee$ - identificar e sugerir atividades pedagógicas complementares, a serem realizadas pelos alunos fora do período letivo; VI - orientar e apoiar os alunos na prática de seus estudos" estas ainda parecem bastante distantes, como se verá na análise das dificuldades da função. (SÃO PAULO, 2012).

Não há qualquer menção ao direito à educação e que as ações do PMEC existem exatamente para garantir esse direito. Isso foi explicitado nos tópicos V e VI da Resolução. Ou seja, a Resolução apontou para o fato de que possivelmente a violência na escola impeça

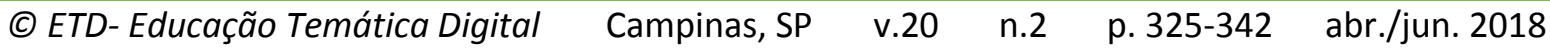


a realização do direito fundamental de aprender. Ao trabalhar com os conflitos e intervir, pretende-se que o objetivo da educação se cumpra. Isso não é visto, ainda, pelos professores mediadores, que estão mais preocupados com as condições de vida dos alunos, com suas "carências" e possibilidades outras, inclusive fora da escola.

\section{PONTOS NEGATIVOS}

O que havia sido apontado anteriormente sobre o perfil do PMEC, suas formas de seleção e recrutamento se fazem sentir no cotidiano destes profissionais. $O$ fato de terem sido "aproveitados" professores que ficariam sem sala de aula, excedentes ou readaptados pesa na realização do trabalho. A queixa de não ser um cargo efetivo, ser uma função, aparece nas falas que dizem respeito ao não reconhecimento por parte dos demais professores, da falta de compreensão, não entendimento da função por parte da equipe de professores, gestores ou direção. "Não ser um cargo efetivo. Por ser uma função, na UE alguns colegas fazem comentários sobre o PMEC e seu trabalho com desdém." (M1).

Que lugar é esse e como está sendo construído duramente pelos profissionais que ali estão? Há outra questão que aparece reiteradamente nas respostas: a exaustão, o trabalho árduo. Esse trabalho árduo parece ser vivido em duas frentes: a interna, frente aos próprios colegas e, externamente, com as dificuldades na montagem e operacionalização da rede de proteção. As queixas são de ausência de resposta, ausência de atuação.

O trabalho, assim, se despotencializa: daí centrar-se a atuação no que é possível, ou seja, no diálogo com os jovens e suas famílias, na tentativa de resolver as questões no âmbito da mediação. A garantia do direito à educação, ou seja, que se pensassem estratégias para a sala de aula e para a aprendizagem exigiria a união de todos, como diz uma PMEC: "colegas que não compreendem, julgam e não reconhecem que somos uma equipe e que a união faz a força" (M13). Isso gera uma frustração que reforça a sensação do trabalho exaustivo e faz com que as dimensões do trabalho, mais políticas e organizacionais ou pedagógicas, como descritas na Resolução, não aconteçam.

Há, assim, um problema de fundação da função que foi inaugurada sem o devido cuidado pela potencialização desse lugar de mediador na escola. As(Os) professoras(es) parecem correr atrás do prejuízo, criando dinâmicas mais personalizadas para tratar as questões, investindo nisso sua simpatia e carisma. Daí ser um trabalho assim definido: "é um trabalho que é às vezes exaustivo pois requer de nós habilidades, perseverança e amor, gostar do que faz" (M3).

\begin{tabular}{|c|c|}
\hline ducação Temática Digital & p. $325-342$ \\
\hline
\end{tabular}




\section{QUE MUDARIA?}

"Eu mudaria as injustiças e preconceitos." (M6).

Novamente percebemos o quão difícil é esse lugar ocupado, um lugar em que há a necessidade de construir a legitimidade e o reconhecimento. As queixas sobre a dificuldade das equipes escolares em reconhecerem o trabalho são postas em duas vertentes: a da não cooperação e a do encaminhamento de demandas que poderiam ser resolvidas em sala de aula "com um pouco de atenção" (M25) por parte dos professores. Nas entrevistas, ver-se-á que o professor mediador ocupa um lugar de quase "coringa" na escola, daí a fala da necessidade de que se delimitem suas funções e se esclareça que lugar é esse: "enumerar as tarefas do professor pois muitas vezes somos obrigados a cumprir outras tarefas diferentes para auxiliar a unidade escolar" (M2).

As dificuldades com a rede de proteção permanecem e se reiteram: esta é uma discussão central em todos os serviços de atendimento. Como constituir uma rede de proteção? Como lidar com os tempos da escola e da necessidade de atendimento, com os tempos das demais organizações do serviço público? Essa é uma questão política que não se resolve via iniciativas individuais de cada professor mediador em sua escola.

Retomando, há dificuldades em trabalhar com redes, em manter as redes vivas e funcionando. Exatamente por conta da complexidade da violência, da heterogeneidade de casos, há demandas diferenciadas (KAMIMURA, 2009). É evidente a necessidade de uma política pública bem delineada de constituição de redes.

\section{OLHANDO MAIS DE PERTO: O DIA A DIA, QUEM PROCURA, QUEM ENCAMINHA...}

A seguir, apresentaremos alguns resultados para as questões das entrevistas, com três professoras mediadoras e um professor mediador. Com as entrevistas conseguimos visualizar melhor o dia a dia das(dos) PMECs, já definido nos questionários como exaustivo, atarefado, com múltiplas demandas:

\footnotetext{
Eu avalio que a mediação de conflitos escolares ainda não está bem pautada entre a direção, vice-direção, coordenação e professores. Muitos pensam que o professor mediador é um folgado que só quando tem um conflito ele trabalha. Eles não veem [...] que esse ano eu tenho, só no segundo bimestre, 124 ocorrências. Entre tudo, né? Entre aluno que vai embora mais cedo, que ficou doente, o pai vem buscar. (M4).
}

Outro exemplo:

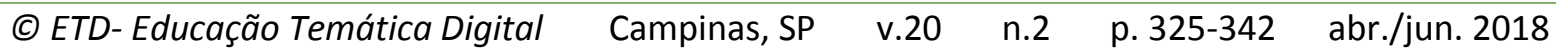


Eu por exemplo sou uma pessoa muito agitada, não consigo ficar parada. Então eu faço de tudo um pouco. Se está um dia tranquilo eu até ajudo o portão, ajudo no intervalo, mas eu trabalho junto mesmo com a criançada. Eles estão às vezes com algum problema em casa. Eles me procuram, vão na minha salinha. Eu tenho uma salinha. Eles me procuram: "O Dona, eu posso falar com a Sra.? Pode sim." Chega lá e conta. Os casos deles, particulares. E aí às vezes estão triste, acabam chorando, e aí eu converso com eles, eu explico porque que a mãe agiu daquela forma, não é porque ela não gosta dele. Não é essa a intenção dela, deles ficarem tristes e chorarem, mas que é para o bem. (M1).

Fazer de tudo... Essa é uma recorrência nas entrevistas, mostrando o quão difícil é pautar o que cabe e o que não cabe ao professor mediador e o que caberia aos professores de sala, à coordenação, à direção. Como já foi assinalado nos questionários, a mediação é, por momentos, o "porto seguro". A salinha da mediação seria um lugar seguro para falar sobre coisas que não é possível falar em outros lugares? No relato de $M 1$, além dos casos disciplinares que são reiteradamente encaminhados, há a procura espontânea, com a salinha funcionando como um lugar de acolhimento para questões particulares, um lugar de aconselhamento.

\begin{abstract}
Nossa. O dia comum é você chega lá na escola, você tem alguns relatórios, você tem alguns deveres a fazer. Aí de repente o inspetor ou o professor traz aluno, porque brigaram, agressão física dentro da sala de aula, ou porque agrediu verbalmente um colega ou mesmo um professor. Aí tem casos em que a gente só conversa. Dialoga com ele, fala que é uma falta de respeito, que isso não pode haver. Outros casos, quando é muito grave, que nem agressão física, a gente faz um relatório, registra no ROE (registro de ocorrência escolar), passa para a direção, porque aí a direção pede para convocar os pais, né? Aí os pais de ambas as partes veem, aí você conversa, pergunta se eles estão de acordo, aí eles se desculpam. As crianças se desculpam. E assim a gente aplica uma norma de conduta com eles, que essa norma de conduta diz que na escola não pode haver esse tipo de comportamento, esse tipo de agressão. E aí fica tudo correto, fica tudo certo. (M2).
\end{abstract}

Neste relato, que complementa bem o primeiro apresentado, aparecem os casos disciplinares que são atendidos na mediação. De fato, não parece haver "mediação" e sim o tratamento de questões disciplinares. A chamada dos pais neste trabalho é reiterada, sendo um recurso usado para que as partes pactuem novas formas de convívio. $O$ trabalho não parece passar pela produção de um diagnóstico e sim pela reiteração da inadequação de determinadas condutas e pela aplicação de uma norma de conduta.

Um dia comum? Desenvolver projetos, ações com os alunos sobre conscientização do que eles podem e não podem. Como normas de condutas escolares, eles devem estar sabendo o que eles devem e não devem fazer dentro da unidade escolar, o porquê, a explicação do porquê disso. Porque muitos, quando eles têm um conflito com o colega, eles pensam que aquilo lá é um agravante tão grande que ninguém pode resolver. Quando você media, conversa com eles, explica a situação e leva ele entender o porquê ele não deveria ter feito aquilo, eles mesmo se surpreendem. É muito legal, eu gosto. Que mais... a gente vem desenvolvendo projetos, estou envolvido num projeto que o governo nos mandou ano passado,

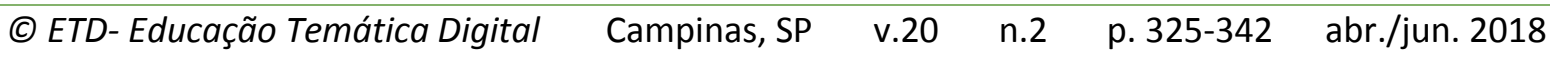


um projeto chamado "Projeto pé no chão", que é a proibição de álcool para menores. Se você quiser dar uma passada lá, dar uma olhada no projeto, dar uma olhada no que eles já fizeram. Na conclusão do trabalho deles, muito legal. (M3).

Nesta entrevista, a mediação trabalha com projetos mais gerais para marcar as normas de conduta, o que se pode e o que não se pode fazer. Mesmo com os projetos acontecendo, parece ser um trabalho centralmente disciplinar, de conscientização de como se comportar no ambiente escolar.

Então eu chego de manhã, e já fico preparado. Porque todo dia vem, todo dia vem os pedidos de socorro dos professores, do diretor, e de outros alunos também. Aí trazendo o problema, às vezes é um xingamento, é um... como se diz... não está fazendo a atividade, o professor se cansa de todo dia estar pedindo para que ele faça aquela atividade que ele não faz. Esses são os mais simples, né? Os piores mesmo às vezes um já vem sofrendo um constrangimento dentro da sala de aula por outro colega, por ser mais feinho, por não estar bem vestido, por estar com um tênis menos valoroso, outro por ter o cabelo diferente, outro por ter o visual diferente do outro. Aí tem esses conflitos. Vem na minha sala a gente identifica porque que desceu. (M4).

Estes relatos revelam exatamente as dimensões do dia a dia das professoras mediadoras. Aparentemente qualquer situação pode gerar um encaminhamento que chega como um "pedido de socorro". Aparecem situações de não adesão às atividades pedagógicas, situações de discriminação, bullying, relacionamento difícil entre os alunos. Em todos os casos, a dinâmica é a da conversa. No caso de M4, há a preocupação de que eles se envolvam e encontrem o caminho para a solução dos problemas, ao contrário de M2 que parece se pautar mais na aplicação das normas de conduta.

Quem encaminha? Professores, inspetores de alunos, os próprios alunos procuram... De acordo com M1, muitos professores consideram que o mediador é um "inspetor de luxo": tudo é encaminhado, principalmente quando estão envolvidas questões disciplinares na sala de aula.

\footnotetext{
Na verdade, é assim, têm professores que às vezes o aluno está sendo humilhado na sala de aula, menosprezado, sendo deixado de lado e ele vai se sentindo muito triste, e aí chega para a professora e diz assim... ou então o aluno está mexendo com ele e a professora não percebeu. Aí ele fala: "Olha professora, posso ir ao banheiro?" A Professora fala: "Pode". Aí ele não vai no banheiro, aí ele vai lá falar comigo. Aí ele fala assim... é. "Você não falou para a professora?" "Não, não falei. (M1).
}

No depoimento de M1, reaparece algo que foi marcante nos questionários, a pouca clareza da função do mediador para a equipe escolar: qual é mesmo a função do mediador escolar dentro da escola? 
Ah... são professores que tem um perfil... é ... às vezes encaminha aluno que não são nem agressões, sabe? O aluno esqueceu o material, o aluno não faz nada, aí o professor encaminha, porque não quer na sala. Mas também não é nossa parte, né. Seria do diretor e vice-diretor a parte de disciplina. Mas ele encaminha porque está incomodando ele de alguma forma na sala de aula. Então: "não quero você aqui nesse momento", então manda para a mediação. Ou caso de crianças com inclusão, que o professor também não sabe como lidar, então a criança não consegue acompanhar. Ela nem tem como acompanhar e o professor não está preparado para essa situação. Manda alguém levar para a mediação. (M2).

Essa situação fica claramente exposta no depoimento de M2: todos encaminham e encaminham questões diversas, não apenas os casos de disciplina, mas os casos em que há desinteresse, falta de cumprimento de atividades escolares. São mencionados os casos de inclusão, quando não se sabe o que fazer com eles. Seria uma forma do professor tentar respirar? Mandar para a mediação? Lembramos que duas funções do professor mediador diziam respeito ao auxílio à aprendizagem, segundo a Resolução n.o 7 de 2012: “V identificar e sugerir atividades pedagógicas complementares, a serem realizadas pelos alunos fora do período letivo; VI - orientar e apoiar os alunos na prática de seus estudos" (SÃO PAULO, 2012). Ou seja, a ideia inicial em torno da função seria a de que, a partir da verificação diagnóstica da situação da escola em termos de vulnerabilidade, seriam propostas uma série de ações preventivas ou intervenções mais gerais que pudessem dar conta dos problemas mais recorrentes no dia a dia. Porém, como conseguir isso se há uma ideia na equipe escolar de que o PMEC é "um inspetor de luxo", se não há um lugar legitimado para ele por não ser um cargo e sim uma função, se não há diálogo e uma atitude de "união que faz a força" na equipe escolar?

Para a minha sala? Professor. [...]. Eu vejo mais o professor, assim, inseguro. Inseguro não de conhecimento, inseguro de lidar, de lidar com o aluno. Ele: "Ah, não vou me envolver nisso, então eu vou passar para frente". [...]. Tem o mediador lá embaixo. Passa bola. $\mathrm{E}$ as meninas vêm descendo, tanto meninas como meninos. (M4)

De uma forma geral, parece que tudo e qualquer coisa pode ser encaminhado ao mediador por todos os atores da equipe escolar, inclusive com a procura espontânea por parte dos(as) alunos(as). Isso não ocorre sem tensões, fazendo com que o cotidiano do PMEC seja descrito como exaustivo e de trabalho árduo, com ele tendo que conviver com a imagem de que "é um folgado que só trabalha quando tem conflito", "é um inspetor de luxo", convivendo com a ambiguidade que cerca a função desde sua fundação em relação à equipe escolar, sem instrumentos, muitas vezes, para acionar a rede de proteção que se revela frágil e inoperante.

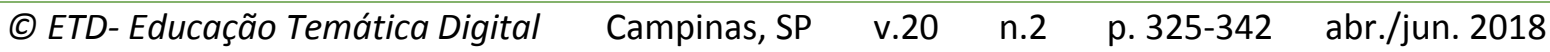




\title{
7 E AGORA? É A ESCOLA MAIS JUSTA?
}

\begin{abstract}
"Talvez", é preciso sempre dizer talvez quanto à justiça. Há um porvir para a justiça, e só há justiça na medida em que seja possível o acontecimento que, como acontecimento, excede ao cálculo, às regras, aos programas, às antecipações, etc. A justiça, como experiência da alteridade absoluta, é inapresentável, mas é a chance do acontecimento e a condição da história. (DERRIDA, 2007, pp. 54-55).
\end{abstract}

A atuação parece mesmo estar centrada na conversa e tentativas de pactuação, fortemente ancoradas no carisma do PMEC. A família, que é vista como origem do problema para alguns, é convocada reiteradamente; de fato, aposta-se em que consiga conter o aluno. Não parece haver um plano de ação minimamente integrado, ou seja, o que cada um dos sujeitos poderá fazer para auxiliar no direito à educação da criança ou adolescente. Sozinho, o que pode fazer é, em sua salinha, conversar. Mesmo assim, as entrevistadas passam uma visão positiva de sua atuação nas escolas, mesmo com as dificuldades apontadas. Haveria menos desavenças, menos brigas, mais diálogo; em resumo: menos ocorrências. Em troca? A solidão, um enorme esforço, a sensação de exaustão. Concluímos nossas entrevistas perguntando se, com a figura do(a) professor(a) mediador(a), a escola teria ficado mais justa.

Algumas respostas:

Mais ou menos, acho que não. Porque assim, a gente não tem autonomia total de resolver tudo. Na escola mesmo que eu trabalho, aí tem casos, que eles aprontam, mas tem que ter a decisão do diretor. Aí o diretor fica mais flexível, ele trata o caso mais como paizão. Aí o aluno sai dali, naquele momento, ele finge que ele está comovido. Daqui a pouquinho ele está fazendo tudo de novo. Você entendeu? É como se fosse assim, alguém passou a mão na minha cabeça, então, amanhã eu posso fazer novamente. (M2).

Bom, pode até no ver dos outros não. Mas na minha visão sim. Se torna um lugar mais justo, por que? Porque quando eles veem que você não vai com aquele intuito de julgar, mas sim de restaurar, você vai com o intuito de ajudar. Ouvir sempre as duas partes envolvidas e buscar a solução da melhor maneira. Muitas vezes não precisa pai e mãe, que eles mesmo chegam na conclusão. E uma outra vez você precisa chamar os responsáveis dos dois para resolver junto. (M3).

Ah sim. Existe mais, existe mais. A coisa deu uma mudada. Até o professor mesmo vê... diz "Poxa vida, eu não posso agir tão energicamente aqui dentro da sala de aula, porque lá na salinha do mediador, ele exerce de uma forma diferente. E o aluno sobe aqui diferente, pode até fazer de novo, ele vem com argumentos, ele vem com outra cabeça". Tem até uma professora de história, ela me chama de o "exorcista". "Oi seu exorcista". A tá... Porque os alunos sobem com uma cabeça diferente, até fazem de novo - esses danadinhos -, mas sobem diferentes. (M4).

Não, mais ou menos, sim, por conta de um canal de diálogo e escuta; sim, porque alguns comportamentos (de professores e alunos) se amenizaram, haveria mais cuidado na hora de falar coisas como "perguntou de onde eu nasci" (M4), menos discriminação e

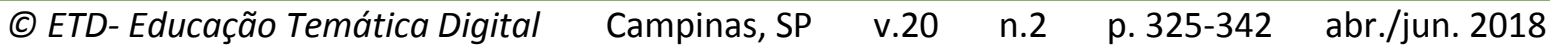


empírico percorremos exatamente estas dimensões: o que está em jogo, quando se instaura a justiça restaurativa e a mediação nas escolas, quais são os conflitos, o quê se deseja corrigir? Quem serão os atores: os indisciplinados, os diferentes, aqueles que brigam, choram, "vão mal" na escola? Apenas os jovens e as crianças ou também os adultos? Como se exercerá esta justiça? Com o conjunto de todos os envolvidos, transformando a escola ou na "salinha"? Com uma professora solitária e sem poder ou com o envolvimento de todas/os da escola?

Retomando: o "quê" da justiça está em questão o seu objeto da justiça. Este objeto, para Fraser se desdobra em três dimensões, sendo a primeira a dimensão econômica, comportando as lutas por redistribuição. A injustiça dessa dimensão está na desigualdade econômica, na má distribuição da renda. Internamente a essa dimensão econômica há uma luta constante, pois não há consenso sobre o que deverá ser distribuído, como, qual o alcance, quem deverá ser contemplado. A segunda dimensão que compõe o objeto da justiça é de ordem "cultural" (o que não significa que se encontre imbricada à dimensão econômica, sem se esgotar nessa ordem), ligada ao status de determinado grupo em uma sociedade: são as lutas por reconhecimento ou contra uma determinada hierarquia de status. A terceira dimensão, que transparece nas lutas sobre qual deveria ser o objeto de atenção da justiça, é de ordem política, implicando na luta por superação de déficits de representação e falta de participação política.

Está em questão o "quem" da justiça: quem é o sujeito da justiça, seu destinatário principal? Os princípios hoje existentes se dividiriam em: o princípio da condição de membro, no marco de uma nacionalidade ou cidadania compartilhada; outro princípio apelaria à condição comum de todos como membros da humanidade; outro grupo apelaria para o princípio da justiça transnacional, do todos afetados, marcando que existem relações sociais de interdependência a considerar. Como alternativa a esses enfoques, que ou limitam excessivamente o marco ou o diluem demais, Fraser propõe um princípio normativo denominado "princípio de todos os sujeitos". Outra questão que cabe mencionar nessa complexa questão do "quem" da justiça é de quem julgará, quem terá legitimidade de mediar, medir, comparar, falar? Trata-se de algo trabalhado por Fraser quando discute o "como" da justiça e que emerge com grande força nos conflitos sociais atuais. Há um outro lado da discussão sobre o "quem", ou seja, aquele que instaura um discurso verdadeiro sobre o "quê", por exemplo, ou o "quem" da justiça. Quais serão as instâncias que julgarão? Os representantes políticos do povo ou o poder judiciário? Os pais ou os especialistas em comportamento? Quem decide a norma, a medida, que uma determinada demanda é justa?

A última questão é a que envolve o "como" será o exercício da justiça: não haveria um acordo sobre como deveriam resolver-se as disputas e demandas sobre a gramática da

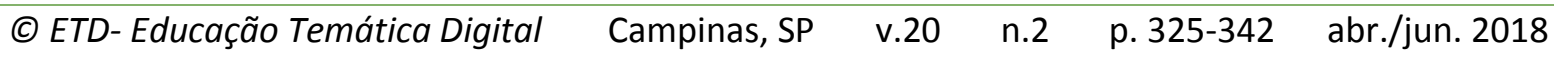


justiça. Quais seriam as autoridades institucionalizadas, como agiriam? Propõe uma teoria que seja ao mesmo tempo dialógica e institucional. Supõe a legitimidade das demandas, da existência de muitas vozes (correntemente dissonantes) que possam se fazer presentes e o desafio de imaginar essas vozes aparecendo em novas instituições democráticas globais. $E$ como pensar esse exercício nas instituições escolares? As políticas que descrevemos tentam dar alguma resposta a esta questão.

Estas seriam, segundo Fraser, dimensões e níveis da justiça anormal, que funcionam como ponto de partida para a ação, para a luta contra as injustiças. Uma última precaução seria problematizar a questão da justiça normal e da justiça anormal, tendo como parâmetro a ideia de justiça reflexiva. Esta seria a forma de contornar o perigo das análises centradas na fluidez, mudança e dilemas da atualidade, invalidando a possibilidade de se perseguir mais justiça. Permitiria manter viva a chama do interesse pela emancipação, acreditando na possibilidade de uma reconstrução da gramática da justiça "de forma que permita al subalterno hablar en términos acreditados" (Fraser, 2008, p. 144). A importância da análise de Fraser é inegável: permite pensar além, e, principalmente, numa perspectiva de liberdade, imaginar possibilidades de justiça, de práticas justas.

Nesta pesquisa, vimos fortemente apresentado o eixo do diálogo, da possibilidade da fala. Retomando novamente Derrida (2007, p. 33), "a violência de uma injustiça começa quando todos os parceiros não compartilham totalmente o mesmo idioma". Como construir a possibilidade do falar em termos reconhecidos, partilhados? Este é um dos grandes desafios da escola justa.

\section{REFERÊNCIAS}

BAUMAN, Zygmunt. O mal-estar da pós-modernidade. Rio de Janeiro: Zahar, 1998.

DERRIDA, Jacques. Força de Lei. São Paulo: Martins Fontes, 2007.

DERRIDA, Jacques. O perdão, a verdade, a reconciliação: qual gênero? In: NASCIMENTO, Evaldo (Org.). Jacques Derrida: pensar a desconstrução. São Paulo: Estação Liberdade, 2005. p. 45-94.

DUBET, François. $\mathbf{O}$ que é uma escola justa: A escola das oportunidades. São Paulo: Cortez, 2008.

DUBET, François. "O que é uma escola justa?”. Cadernos de Pesquisa, São Paulo, v. 34, n. 123, p. 539-555, set./dez. 2004. Disponível em:

http://www.scielo.br/pdf/cp/v34n123/a02v34123.pdf. Acesso em: 15 mar. 2016.

FOUCAULT, Michel. O governo de si e dos outros. São Paulo: Martins Fontes, 2010.

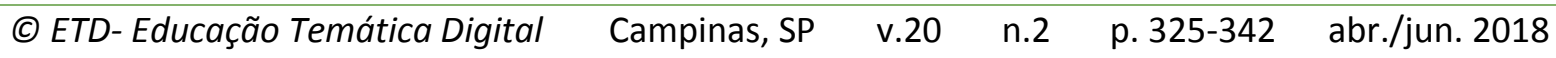


FRASER, Nancy. Escalas de justicia. Traducción: Antoni M. Riu. Barcelona, Espanha: Herder Editorial, 2008.

KAMIMURA, Akemi. A efetivação dos direitos humanos: o desafio do direito no atendimento interdisciplinar a vítimas de violência. 2009. 191 f. Dissertação (Mestrado) Faculdade de Direito, Universidade de São Paulo, São Paulo, 2009.

PRÖGLHÖF, Patrícia de Oliveira Nogueira. Violência nas escolas e políticas públicas: um estudo sobre a formulação do Sistema de Proteção Escolar e Cidadania. São Paulo: Fundação Getúlio Vargas, 2015.

RICOEUR, Paul. O Justo. São Paulo: Martins Fontes, 2008.

SÃO PAULO. Secretaria Estadual de Educação. Resolução SE n.o 07, de 19 de janeiro de 2012: Dispõe sobre o exercício das atribuições de Professor Mediador Escolar e Comunitário do Sistema de Proteção Escolar, e dá outras providências. Disponível em: http://www.mpsp.mp.br/portal/page/portal/Educacao/Legislacao/Estadual/RES SEE 0712190112 ProfessorMediador.pdf . Acesso em: 13 jan. 2016.

SCHILLING, Flávia. Educação e direitos humanos: percepções sobre a escola justa. São Paulo: Cortez, 2014.

SCHILLING, Flávia. Igualdade, desigualdade e diferenças: o que é uma escola justa? Educação e Pesquisa, São Paulo, v. 39, p. 31-48, 2013.

SLAKMON, Catherine; MACHADO, Maíra Rocha; BOTTINI, Pierpaolo Cruz (Org.). Novas direções na governança da justiça e da segurança. Brasília, DF: Ministério da Justiça, 2006.

TIBÉRIO, Wellington. A judicialização das relações escolares: um estudo sobre a produção de professores. 2011. 155 f. Dissertação (Mestrado) - Faculdade de Educação, Universidade de São Paulo, São Paulo, 2011.

\footnotetext{
' Revisão gramatical do texto sob a responsabilidade da autora
}

(C) ETD- Educação Temática Digital Campinas, SP $\quad$ v.20 $\quad$ n.2 $\quad$ p. $325-342 \quad$ abr./jun. 2018

